The continents are likely to be the major source of nitrogen oxides and these are the places to look for evidence of atmospheric reactions. There is certainly a case for an experiment of this type to continue if only to confirm that many compounds released from modern industry are destroyed before they can reach the ozone layer in the stratosphere. It should concentrate on unpolluted continents in tropical latitudes and it should include measurements of transient products such as aldehydes and nitro compounds. These are easier to measure than radicals but provide the sort of information which is necessary to test theories of atmospheric oxidation.

\title{
Cracks in rocks under stress
}

\author{
from Barry Atkinson
}

MICROCRACKS influence many of the physical properties of rocks. Strength, transport, elastic and inelastic characteristics are all highly dependent upon the size, shape, number and distribution of microcracks. These physical properties change dramatically as crack characteristics are modified under stress.

In earthquake prediction, the exploitation of oil, gas and water bearing formations, nuclear waste disposal, and heat extraction and storage, the prediction of in-situ physical properties from models of rock microcracks is of great importance but has, so far, been rather unsuccessful. The basic problem is that, despite many laboratory studies, we have only a rudimentary idea of the actual modifications that cracks undergo in stressed rocks. M.L. Batzle, G. Simmons and R.W. Siegfried of MIT have recently attempted to overcome this problem by making direct observations of crack closure in granite and diabase under uniaxial compressive stress (J. geophys. Res. 85; 7072, 1980).

The MIT group placed a small hydraulic press inside a conventional scanning electron microscope (SEM) so that they could subject cylinders about one $\mathrm{cm}$ in diameter and two $\mathrm{cm}$ long to uniaxial stresses of up to $30 \mathrm{MPa}$. A portion of the lateral side of the core was ground flat and bombarded with ionized argon to remove the damaged surface before examination in the SEM. Stress-strain measurements were also made on similar cores in the press but outside of the SEM. Although SEM studies have been made before on specimens subjected to tensile in situ stresses, this is the first time that a compressive stress has been so studied.

Westerley granite and Maryland diabase were examined in the 'natural' state and after slowly heat cycling to $500^{\circ} \mathrm{C}$ and $700^{\circ} \mathrm{C}$, respectively, to increase crack porosity. Westerley granite is a typical crystalline rock with initial crack porosity of about 0.2 per cent and a total porosity of about 1 per cent. Maryland diabase is unusual in that it has no measureable crack porosity and a low total porosity of 0.1 per cent. Westerley granite consists of roughly equidimensional feldspar, quartz and biotite mica grains averaging 800 micrometres in diameter. Maryland diabase consists mainly of equidimensional grains of feldspar and pyroxene averaging 200 micrometres in diameter.

In general, the response of cracks to stress confirmed those predicted from microscopic examinations made at zero stress (Kranz, R.L. Int. J. Rock. Mech. Mining Sci. Geomech. Abstr. 16; 37, 1979) and from deformation measurements made under applied stress (Brace, W.F. et al. J. geophys. Res. 71; 3939, 1966). Numerous factors influence the behaviour of cracks, including orientation, shape, source, and the proximity of other fractures.

The main conclusion of the recent work, however, is that pre-existing cracks in these rocks behave quite differently to those induced by heat cycling. Pre-existing cracks have walls that are irregular, etched and pitted, and poorly matched. Under stress, closure is incomplete with many portions remaining open and interconnected. The shape, or aspect ratio, continually changes as stress increases. Thermally induced cracks are also irregular but the walls are more perfectly matched and tend to close more completely, unless propped open by very small grains or debris.

Although pre-existing fractures can be re-opened, widened, extended, or closed, depending on a host of interrelated factors, in general those cracks oriented close to the direction of maximum stress tend to open, whereas those oriented nearly perpendicular to the maximum stress tend to close.

New cracks created in the laboratory by stress or temperature usually have the irregular but well matched characteristics of thermal fractures. This is important because the precise nature of the crack response to stress determines the trends in dependent physical properties. New fractures will close easily and hence lead to a large change in physical properties with stress as compared with the more inefficient

Barry Aikinson is NERC Special Research Fellow at the Geology Department, Imperial College, London. closing of pre-existing cracks.

How then do induced cracks attain the characteristics of pre-existing cracks? A key element in this seems to be the extent to which cracks are modified by the circulation of water at high temperatures. Under these conditions grains become rounded and crack walls etched and pitted (Potter, J.M. Rep. LA-7224-T, Los Alamos Sci. Lab., 1978) and begin to resemble pre-existing cracks.

The fact that almost complete closure of thermal and stress-induced cracks can occur lends support to D.J. Holcomb and J.L. Stevens assertion that reversible Griffith cracks can explain all of the observed attributes of rock dilatancy $(J$. geophys. Res. 85; 7101, 1980). They cast doubt on the widely used sliding crack model of dilatancy, in which dilatancy arises from the formation of tensile cracks at the ends of a large number of sliding shear cracks, partly because a shear crack model cannot explain the stress memory rocks exhibit and especially because shear cracks are only rarely observed in some dilatant rocks (Tapponier, D. and Brace, W.F. Int. J. Rock Mech. Mining Sci. Geomech. Abstr. 13; 1976). On the other hand, long, narrow cracks preferentially oriented parallel to the maximum compressive stress are very common in some rocks and these Griffith cracks can apparently explain all of the experimental results on rock dilatancy, provided that the cracks can open and close reversibly under stress.

A problem arises, however, because most studies of stressed cracks in rocks have been made on low-porosity, wellcemented crystalline rocks. Less wellcemented, high-porosity sedimentary rocks with more point contacts and fewer interlocking grains have quite different initial preferred orientations and distribution of microcracks. Recent experimental studies have shown that the differences in peak strength, the localization of deformation to give a main fault, and some water-weakening effects can be qualitatively explained in terms of the initial microstructure (Hadizadeh. J., Thesis, University of London, 1980).

Two limitations of the MIT study are that we are not sure their observations are typical of the bulk of their specimens. They examined sections that were within $1 \mathrm{~mm}$ of the surface, and the role of stress corrosion crack growth was not investigated in the high-vacuum environment of the SEM. Insitu tensile tests, however, show that stress corrosion can be a significant factor (Swan, G. Res. Rep., Tulea 1980:01, University of Lulea).

It would now be valuable to extend insitu observations to higher stresses and temperatures and more complex polyaxial stress states. At present this is not possible and one is forced to examine at zero stress and ambient conditions specimens that have been retrieved from more exotic conditions. 